\title{
sciendo
}

DOI: $10.2478 /$ jolace-2021-0020

\section{Between the urge to know and the need to deny: trauma and embodied memories in Margaret Atwood's Cat's Eye (1988)}

\author{
Ikram Lecheheb \\ University of Skikda, Algeria \\ ikramlecheheb21@gmail.com
}

\begin{abstract}
The study intends to explore and analyze the role of corporeality in expressing earlier repressed traumatic events as manifested in Margaret Atwood's Cat's Eye (1988). It shows that the protagonist, Elaine Risley, is imprisoned within the prison of her traumatic past memories that still live involuntarily in her present, shaping her language and behavior. It equally reveals that the connection between the protagonist's body and her conscious self is damaged due to overwhelming effects of her trauma; triggering her body to unconsciously project those traumatic memories. The study specifically examines how Atwood's protagonist's trauma returns through the cracks of her consciousness in a form of auditory and verbal hallucinations and dissociation from herself. In order to probe the connection between soma and trauma in Atwood's novel, the study leans on a distillation of psychological theorizations; particularly Sigmund Freud's emphasis on the somatic expression of trauma. Through a textual analysis of Atwood's novel, the study highlights that trauma is responsible for the protagonist's anxiety, fear and loss of language, seeking to examine how Atwood's protagonist strives to heal from her earlier traumatic memories through different mediums including art.
\end{abstract}

Key words: Margaret Atwood, Cat's Eye, corporeality of trauma and healing process.

\section{Introduction}

In different psychoanalytic studies, it is shown that individuals who are exposed to severe trauma experience speechless terror. They cannot speak about their psychic wounds at a linguistic level; this is why they unconsciously deploy corporeality as a medium through which their unspeakable experiences can be communicated. It is worth noting that although Margaret Atwood's novel has been a rich subject for scholars of trauma, corporeality of trauma, in Cat's Eye, has not yet taken its place in their critical studies. On this basis, it is the intention of this study to explore and analyze the concept of the corporeality of trauma as form of enunciating Elaine Risley's trauma. The study is devoted to show that the protagonist's trauma is not only materialized in the form of hearing ghost voices or seeing visible bodies but it is also re-enacted via dissociative symptoms such as, fainting, self-mutilation, anorexia nervosa, bulimic behavior and uncontrollable actions and behaviors. In order to achieve these objectives, one should answer the following questions: What do psychoanalysts have to inform us on the transformation of traumatic silenced events into corporeal unconscious reactions. How can this be applied to the traumatized protagonist in Atwood's Cat's Eye? These queries are prefatory to other related questions: How communicative is the language of the protagonist's body in enunciating her trauma. And how can a trauma victim successfully heal from trauma? The study exploits the wealth of psychoanalytic theorizations to outline the history of the corporeality of trauma and to analyze the various somatic manifestations of trauma in Atwood's Cat's Eye. 
Margaret Atwood's Cat's Eye (1988) explores the life of Elaine Risley, a middle aged painter, her everyday experiences and her inner sensations intermingled with her past memories. Like Atwood's other protagonists, Elaine narrates events retrospectively to reflect her childhood traumatic memories. The novel reflects the facets of the bildungsroman in dealing with the character's development from childhood till adulthood especially the theme of self-discovery. It also examines the theme of friendship through Elaine's connection with Carol Campbell, Grace Smeath, and Cordelia who takes the leadership in harassing Elaine during her childhood. Throughout the novel, Atwood uses images as "The middle of the river" (13), and "The middle of the bridge" (13) to symbolize that Elaine is torn between the present and the past. In dealing with trauma as a problem of knowing and not knowing in Atwood's fiction, one must also engage in exploring how Elaine's trauma, in Cat's Eye, becomes recognizable and spoken via her body.

To highlight the connection between soma and trauma in Atwood's Cat's Eye, the study refers to the history of the concept of the corporeality of trauma as it appears in different psychoanalytic studies. It is not surprising that one of the earliest of these works is by Sigmund Freud, in which he focuses on trauma projection via soma. Freud asserts, in his studies, that the appearance of mental disorder is connected with the return of repressed memories. He charts the psychoanalytic implicit connection between the body, the return of repressed past memories and the voice. Freud's references to the notion of hearing voices are few as he does not actually construct a systematic theory of the matter. He, rather, deals with psychosis and he considers hysteria, obsessional neurosis and hallucinatory confessions as forms of defence mechanisms. He maintains that hallucinations are a product of unconscious conflicts that the individual cannot control.

Freud's references to hallucinations and hearing voices appeared in Studies in Hysteria (1895): "The voices owed their origin to the repression of thoughts which [...] were in fact selfreproaches about experiences that were analogous to childhood trauma" (Freud, 2004, p. 305). In Beyond the Pleasure Principle (1920), Freud sheds light on repetition compulsion showing that ungraspable traumatic experiences haunt traumatized individuals in a form of hearing voices. To reinforce his argument, Freud reads Torquato Tasso's La Gerusalemme Liberata, in which Tancred mistakenly killed his beloved Clorinda. As time runs, Tancred hears the voice of Clorinda; "whose soul is imprisoned in the tree [...] complaining that he has wounded his beloved again" (Freud, 2003, p. XIV). Freud's work illustrates that trauma can be manifested again in a form of hearing repetitive voices; that is, he points to the existing bond between the return of the repressed, repetition compulsion and the voice which "has been forgotten and repressed" (Freud, 2003, p. 37).

Again, in Studies in Hysteria, Freud, for instance, indicates that there is a connection between earlier traumatic memories and neurotic symptoms. The hysterical body, he explains, projects trauma via neurological conversion symptoms, where earlier traumatic memories return to the conscious mind to be manifested again via the metaphor of the "Foreign Body" as fresh memories. He mentions that "the memory of trauma operates like a foreign body which still can be regarded as a present agent long after it has penetrated" (Freud, 2004, p. 10). Again, in Beyond The Pleasure Principle, Freud indicates that repressed memories cease to remain in the past and linger as a daunting agent in the present, molding the subject's actions and behavior. In search of enunciating "the wound of the mind," Freud refers to corporeality as not only a medium that works through earlier traumatic memories but also as a way of releasing the traumatized subject from the shackles of trauma, finding some solace from the haunting nature of those dramatic situations. Theorists of trauma as Cathy Caruth, Shoshana Felman, Dominick 
Lacapra, among others, have coincided with Freud's view that soma plays an important role in the projection of earlier trauma.

Different recent psychoanalytic studies draw on Freud's metaphoric reference to the role of soma in enunciating earlier traumatic memories. In Powers of Horror: an Essay on Abjection (1982), Julia Kristeva, for instance, coins the term "Abjection" to refer to humans' reactions to traumatic events. She highlights that abjection is associated with polluted and contaminated feelings which lead subjects to feel a sense of nothingness in the way they cannot distinguish between the self and the other or what Freud has referred to as the double. By the same token, in The Body in Pain: The Making and Unmaking of the World, Elaine Scarry argues that due to the persisting nature of traumatic events, the traumatized person suffers from a separation between the body and the mind. She asserts that "for what the process of torture does is to split the human being into two [...leaving] only latent distinction between the self and the body, between me and my body" (Scarry, 1985, pp. 48-49).

Nicolas Abraham and Nicholas Rand's "Notes on the Phantom: a Complement to Freud's Metapsychology" is another touchstone work in the field of the corporeal enunciation of trauma. They argue that trauma returns through the cracks' of the individual's consciousness in the form of the phantom. They describe the phantom as "a meta-psychological fact," adding that "what haunts are not the dead, but the gaps left within us by the secrets of others" (Abraham and Rand, 1987, p. 287). They add that repressed memories return in a shadowy manner to disturb the subjects' time so that they no longer distinguish between the present and the past. Abraham and Rand's argument on the haunting nature of earlier traumatic events converge with Judith Lewis Herman's central idea in Trauma and Recovery: the Aftermath of Violence from Domestic Abuse to Political Terror. She coins the term "Chronic Trauma" suggesting that the haunting nature of earlier traumatic memories forges a state of "double think" (Herman, 1992, p. 3), in which the subject's mind goes back and forth in time with the disturbing intersection of the past and the present.

Generally speaking, different psychoanalytic studies reveal that repressed memories surface not only in the form of voices but also in the medium of visible bodies, phantoms; creating a sort of psychological disintegration and dissociation in the traumatized subject's actions and behavior. In other words, dissociation is another form of expressing earlier traumatic events. The traumatized subject re-enacts those traumatic memories via dissociative symptoms; namely uncontrollable actions and behaviors: self-mutilation, anorexia nervosa, bulimic behaviors, derealization and depersonalization. In dealing with dissociation, as a form of reflecting trauma, Robert Jay Lifton's term of "The Second Self" is needed here. Lifton employs the concept to demonstrate that due to various stressful experiences, the traumatized person experiences a lack in the personality's integration. This lack gives rise to different dissociative parts of the same personality (Lifton, 1995, p. 137). Thus, Lifton's study shows that the dissociative body is a means through which earlier traumatic events are enunciated. In her essay "Embodied Memory, Transcendence, and Telling Recounting Trauma, Re-establishing the Self," Roberta Culbertson coins the concept of "Body Memory," referring to the role of the body in working through trauma. She notes that traumatic memories are "not known in words, but in the body" (Culbertson, 1995, p. 170). Roberta adds that these memories "obey none of the standard rules of discourse" since "they are the self's discourse with itself and so occupy that channel between the conscious and the unconscious that speaks the body language" (Culbertson, 1995, p. 178).

Recent psychoanalytic and clinical studies shed light on trauma and its correlation with dissociation. In her The Dissociative Mind, Elizabeth F Howell, for instance, explains that severe 
childhood trauma has "profound effects on personality development and can lead to the development of Dissociative Identity Disorder (DID), other dissociative disorders, personality disorders, psychic thinking, and a host of symptoms such as anxiety, depression, and eating disorders" (Howell, 2005, p. IX). Howell specifies that dissociation is a "rigid separation of parts of experience including somatic experience, consciousness, affects, perception, identity, and memory" (Howell, 2005, p. IX). She adds that traumatic experiences return to consciousness in "somatosensory modalities, rather than becoming part of narrative experience" (Howell, 2005, p. 28). Dissociation becomes a main concern in contemporary psychoanalytic studies to the extent psychiatrists and clinicians propose therapeutic methods to not only decrease daily stress but also to avoid the side effects of dissociation as a coping strategy.

In The Body Keeps the Score: Brain, Mind, and Body in the Healing of Trauma (2014), Bessel Van der Kolk explains the brain's adaptive response to daily stress. He also points to the impact of childhood trauma as child abuse and neglect on the subject's psyche. He shows that the persisting nature of traumatic events cause a split-off of the self in the way that the brain loses its capacity to evaluate danger and therefore, the body, from Van der Kolk's approach, becomes disconnected. Van der Kolk demonstrates that action is the key in regulating the self at traumatic times. Essentially, he proposes that body actions are a medium through which the nervous system can be calmed at times of stress. According to Van der Kolk, (2014, p. 63), "knowing the difference between top down and bottom-up regulation is central for understanding and treating traumatic stress." The quote implies that Van der Kolk's strategy in erasing traumatic memories and daily stressful events is based on the subject's reactivation of the sense of the self through somatic actions.

In literature, many of trauma novels are characterized by the depiction of the characters' inability to express their psychic wounds at a linguistic level. Authors focus on soma as an alternative voice through which their characters portray their speechless terror and psychic wounds. Flannery O'Connor's Wise Blood (1952) is an example in which Hazel Motes blinds himself with the quicklime as a re-enactment of earlier memories. Alice Walker's Color Purple (1982), Kathryn Harrison's Thicker Than Water (1991), Edwidge Danticat's Breath, Eyes, Memory (1998) and Delillo's The Body Artist (2001) are other examples of literary works, in which the materiality of trauma and its representation are projected through the protagonists' dissociative actions. In The Trick is to Keep Breathing, Janice Galloway provides a graphic depiction of how Joy Stone re-enacts her psychological pain after the death of her lover, Michael, via anorexia nervosa as a facet of dissociation. Galloway gives a detailed description of how Joy stops eating through her incident with a can of vegetable soup. Joy declares:

I found the opener and dug it into the top, lifting it higher with each turn of the handle. Some of the stuff inside smeared on my knuckle. It felt slimy, unpleasant. Inside the can the surface was a kind of flattened jelly dark red with bits of green and yellow poking through. Watery stuff like plasma started seeping up the sides of the viscous block. It did not look like food at all (Galloway, 1989, p. 38).

\section{Corporeal manifestation of trauma in Margaret Atwood's Cat's Eye}

From a psychoanalytic perspective, the study hypothesizes that Atwood's protagonist's trauma returns through the cracks of her consciousness to be manifested in a form of hearing ghost voices, seeing visible bodies and dissociating from herself. It is important to reveal that different studies have dealt with the portrayal of trauma in Atwood's Cat's Eye. The concept of corporeality of trauma, however, has not been researched in Atwood's novel. As an illustration, 
Chinmoy Banerjee (1990) and Brooks Bouson (1993) examine the novel formally in connection to narrative. Other Atwood's scholars as Laurie Vickroy, in "Seeking Symbolic Immortality: Visualizing Trauma in Cat's Eye," suggests that Elaine becomes aware of her childhood trauma through painting: "Elaine's bond to her disturbing past is revealed in the traumatic residues of emotional constriction of effective eruptions in her art. Atwood depicts the artistic process as a safe environment that both expresses and disguises personal anguish and as a form of personal agency" (Vickroy, 2005, p. 130); while Christa Schonfelder, in "(Re) Visions of the Buried Self: Childhood Trauma and Self Narration in Margaret Atwood's Cat's Eye," focuses on themes of the quest for the identity and self-narration. She also emphasizes the connection between writing and trauma as a way that the protagonist can narrate her earlier traumatic memories. According to Schonfelder (2013, p. 271), "Cat's Eye highlights how trauma tends to push processes of self-narration and self-representation to its limits. It explores how "trauma related crises of identity and memory function as considerable obstacles to narration." Research leads us to the fact that the body of criticism dealing with trauma representation via corporeal manifestations in Atwood's Cat's Eye is not tackled before. On this basis, the above-mentioned review of literature enlightens the current discussion in the way it raises more questions of how corporeality of trauma is represented in Atwood's Cat's Eye. Unlike the previous studies, this study will examine trauma in the novel from a new approach by presenting all the corporeal aspects of trauma manifestation and how the protagonist heals from the shackles of her earlier traumatic memories.

During her childhood, Elaine lived as a tomboy due to her parents' work. She never dealt with female characters. For that reason, when she encounters the three girls, she sees them as role models. She particularly sees Cordelia as a mother. Atwood depicts Elaine's relationship with the girls as unhealthy from the beginning because they humiliate her to be a vulnerable individual. They refer to her failings and her weaknesses, mocking the way she walks, the way she eats and the way she laughs; they even bury her in a hole. Although Elaine tries to forget about this incident, it is "the point at which [Elaine] lost power" (Atwood, 1988, p. 126). Largely speaking, Cordelia is seen as the principal tormentor since she keeps harassing Elaine and making her feels that she is "nothing" (Atwood, 1988, p. 47). Due to the girls' maltreatment, Elaine falls into depression, self-hatred and harming herself. During her adolescence, she represses the memories of her childhood, declaring "I am happy as a clam: hard-shelled, firmly closed" (Atwood, 1988, p. 237). Here, the "closed clam" stands for ultimate isolation; building a shield to seclude traumatic memories out of all her consciousness. In "Traces of Shame: Margaret Atwood's Portrayal of Childhood, Bullying and its Consequences in Cat's Eye," Bethan Jones argues that Elaine "becomes the victim of psychological bullying that scars her and infiltrates her mind and language" (Jones, 2008, p. 30). In her retrospective narrative, Elaine shows that she is determined to forget the past memories for ever, avoiding any direct engagement with them; she prefers to shut things out and to forget all what is linked to her childhood. Her trauma, however, lurks under the surface and it returns to her consciousness in the form of hearing ghost voices, seeing visible bodies and dissociating from the self. This latter has two functions. On the one hand, dissociation serves as a coping strategy at the time of the girls' bullying of Elaine. On the other hand, it is a corporeal enunciation of Elaine's traumatic experiences in her adulthood.

\section{Hearing voices in Cat's Eye}

In Cat's Eye, Atwood uses two voices in narrating the events; that is, the first voice is the voice of Elaine who narrates the events of the present time as an adult while the second voice 
can be seen as Elaine's unconsciousness, which no longer able to suppress the past memories. Banerjee mentions, "We might say that in the first voice Elaine speaks and in the second voice her past speaks to her [...] the second voice narrating the past in almost toneless, an inner voice that we may call unaddressed because it is the rising of memory to consciousness" (Banerjee, 1990, p. 515). In the novel, Atwood touches upon the issue of trauma manifestation in the form of hallucinations and hearing voices. The vestiges of the narrator's past continue to haunt her in the form of hallucinations and hearing voices especially after her return to Toronto. Elaine does not only remember characters from the past, but she interacts and converses with them through hearing voices and hallucinations. The narrator's psychological disorder and schizophrenic situation during adulthood is also bred by the unhealthy and failed marriage with Jon. The latter devaluates Elaine and comments that her paintings are irrelevant. Jon can be seen as the guide who pushes the narrator on her downward journey and her descent into the dark side of the self.

During adulthood, the narrator's center can no longer hold; that is, due to the fragility of her consciousness, Elaine's traumatic memories come again to the surface. Elaine remembers her childhood memories with the three girls. She remembers how they humiliate her to be a vulnerable individual. Elaine narrates about her relation with Cordelia, asserting, "She puts an arm around me, gives me a little squeeze, a squeeze of complicity, of instruction. Everything will be alright as long as I sit still, say nothing, reveal nothing. I will be saved then, I will be acceptable once more. I smile, tremulous with relief, with gratitude" (Atwood, 1988, p. 138). She expresses and relives her fear of Cordelia, "A wave of blood goes up to my head, my stomach shrinks together, as if something dangerous has just missed hitting me" (Atwood, 1988, p. 299).

Remarkably, Elaine strives to hide that she hears authoritative voices which order her to put an end of her life. For instance, when Elaine becomes despaired due to her husband's infidelity, she hears the voice of Cordelia pushing her to kill herself, "It will kill me suddenly. I will be walking along the street, thinking of nothing in particular [...] All I will hear will be that small voice, inviting and conspiratorial, gleeful, urging me over. I know I am capable of such a thing" (Atwood, 1988, p. 441). In another occasion, Elaine notes that the images of the dead and her tormentor Cordelia unexpectedly and repeatedly haunt her to the extent she becomes determined to harm herself. In the emergency, Elaine refuses neither to confess that she hears human voices nor to tell anyone about what happened to her during childhood. Later on, Elaine declares that she is haunted by her childhood memories to the point she declares that an embodied voice urges her to commit suicide. She mentions, "When I hear the voice, not inside my head at all but in the room, clearly: do it. Come on. Do it. This voice does not offer a choice; it has the force of an order" (Atwood, 1988, p. 439). In another incident, Elaine notes that "the voice of a nine-year old child" haunts her in an intrusive manner; "You can come in now, says the voice of Cordelia from inside the room. I look at the closed door, at the doorknob, at my own hand moving up if it is no longer a part of me" (Atwood, 1988, p. 139).

In her fiction, Atwood deals with the theme of schizophrenia as a symptom of her protagonists' sufferings. For instance, in Alias Grace, Grace, due to the death of her friend Mary Whitney, is described as a traumatized schizophrenic individual who hears ghost voices. Grace refers to her current situation and the haunting nature of this memory as "a feeling of being torn open; not like a body of flesh [...] but like a peach; and not even torn open, but too ripe and splitting open of its own accord. And inside the peach there is a stone" (Atwood, 1996, p. 79). In Cat's Eye, Elaine becomes schizophrenic due to her traumatic memories. She indicates that she cannot feel anything except falling apart and becoming detached, unable to love 
anyone. She also falls into depression. Her schizophrenia is revealed through her paranoia, her belief that she is watched and her hallucination. In different incidents, Elaine's interior monologues project her psychic breakdown and her schizophrenia.

\section{The foreign body in Atwood's Cat's Eye}

It should be noted that several theorists including Freud, Otto Rank, Ralph Tymms and others give insight into the concept of the double. These theorists converge in the notion that the archetype of the double is a dimension of the foreign body. They highlight that the double is associated with the individual's psychic split of the self, elucidating that the subject creates the image of the double as a part of the ego's defensive measure. Significantly, Freud and Rank postulate that the concept of the double is also associated with mirrors and reflections. Accordingly, in her fiction, Atwood deploys the body or the foreign body as an important tool through which unknown feelings and unspeakable memories can be expressed. In an interview with Elizabeth Meese, Atwood declares that "the body concept has always been a concern of mine [...] I think that people very much experience themselves through their bodies and through concepts of the body which get applied to their own bodies" (Meese, 1986, p. 104).

In her critical book Negotiating with the Dead, Atwood utilizes the mirror imagery to focus on the theme of the double through discussing Lewis Carroll's Alice in Wonderland. Atwood highlights that Alice "Goes through the mirror and then there is only one Alice, or only one that we can follow. Instead of destroying her double, the real Alice merges with the other Alice- the imagined Alice, the dream Alice, the Alice who exists nowhere" (Atwood, 2002, pp. 49-50). In Cat's Eye, Atwood uses mirrors, marbles, glasses, and eyes to not only reflect the theme of the double, but also to show that the character creates the image of the double to overcome certain sorts of fear. Atwood depicts that Elaine, in her childhood, was fascinated by reflective surfaces. When she studies fine arts at college, she paints "Paintings in which there are pearls, crystals, mirrors, and shiny details of brass" (Atwood, 1988, p. 382). Atwood also depicts that Elaine frequently checks herself in the mirror, "Maybe it was as simple as that eye problems. I am having that trouble myself now: too close to the mirror and I am a blur, too far back and I cannot see the details. Who knows what faces I am making? What kind of modern art I am drawing onto myself? (Atwood, 1988, pp. 5-6). In Milena Nikolié's perspective, "The mirror motif reveals the psychological state of Elaine's mind" (2017, p. 107).

Due to her earlier traumatizing events, Elaine, during adulthood, experiences periods of paranoia, depression and anxiety. Trauma disrupts her life to the extent she becomes disconnected from her real self. She asserts, "I feel as if my body is dissolving and I am being drawn up and up, like thinning mist, into a vast emptying space" (Atwood, 1988, p. 123). Day by day, Elaine suspects that she is divided, "I am afraid I will find out that there is someone else trapped inside my body; I will look into the bathroom mirror and see the face of another girl, someone who looks like me but has half of her face darkened, the skin burned away" (Atwood, 1988, p. 251). Through Atwood's use of various signs and clues to the narrator's dispersed and fragmented self, one may recognize that Elaine's body becomes foreign to her,

[She] begin[s] to spend time outside [her] body without falling over. As these times [she] feel [s] blurred, as if there are two of [her], one superimposed on the other, but imperfectly. There is an edge of transparency and beside it a rim of solid flesh that is without feeling like a scar. [She] can see what is happening, [she] can hear what is being said to [her], but [she] [does] not have to pay any attention. [Her] eyes are open but [she] [is] not there. [She] is off to the side" (Atwood, 1988, p. 205). 
In his studies on trauma manifestation and its return to the individual's consciousness, Freud elucidates that past traumatic memories return to the subject's consciousness in uncanny manner or what he calls the foreign body. In their "Notes on The Phantom: A Complement to Freud's Metapsychology," Abraham and Rand work within the Freudian theory indicating that repressed memories haunt the traumatized individual in a form of a phantom "to objectify, even under the guise of individual or collective hallucinations, the gap produced in us by the concealment of some part of a loved one's life produced in us" (Abraham and Rand, 1987, p. 287). From the critics' perspective, the phantom rises into the consciousness of the individual to break the trans-generational silences, the gaps, and the cryptic constructions buried in the unconscious. To put it differently, the phantom compulsively triggers traumatized individuals to tell the psychic wounds of their predecessors. In Toni Morrison's Beloved (1987), as a case in point, Beloved not only embodies Afro-Americans' collective traumas but she obsessively provokes Sethe to both remember and tell these traumas.

Abraham and Rand go a step further exploring the relation between the body, the voice and trauma. They show that the stranger/phantom embodies the silences and the gaps. These latter appear in the phantom's voice and words, "the phantom's periodic and compulsive return works like a ventriloquist, like a stranger within the subject's own mental topography" to work through the subject's past memories (Abraham and Rand, 1987, p. 289-90). In Elaine's case, her childhood memories return to the surface in a form of a shadow or a specter. Elaine declares that "She may have given up on it. I am expected to behave as if nothing has ever happened. But it is hard for me to do this; because I feel I am always being watched" (Atwood, 1988, p. 143). In her staying in the window, Elaine declares, "I feel a touch on my arm, a chilly jump of the heart" (Atwood, 1988, p. 368). Later on, Elaine confesses that the intrusive memory of the girls' bullying becomes representable to her in a corporeal form. On this basis, Elaine asserts that she is "Growing confused [herself]. [Her] memory is tremulous, like water breathed on. For an instant [she] see[s] Cordelia and Grace, and Carol, walking towards [her] through the astonishing whiteness of the snow, their faces in shadow" (Atwood, 1988, p. 465).

Atwood specifically highlights that Elaine is engulfed by images of her childhood memories with Cordelia. In the novel, there is a chapter entitled "Half a Face," in which Cordelia tells a story about twin sisters, "A pretty one and one who has a burn covering half her face" (Atwood, 1988, p. 249). In the story, Cordelia narrates that the disfigured sister commits suicide, "In front of the mirror out of jealousy, her spirit goes into the mirror" (Atwood, 1988, p. 249) to take over her sister's body. Atwood employs the story of the disfigured face to highlight the fragmentation of Elaine's self. In "Names, Faces and Signatures in Margaret Atwood's Cat's Eye and The Handmaid's Tale," Jessie Givner maintains that "The half face is one of the most pervasive images of disfiguration" (Givner, 1992, p. 66). In her artistic gallery, Elaine refers to the disfigured face. The painter makes a portrait of her friend Cordelia, but the painter has "An odd title because Cordelia's entire face is visible. But behind her, hanging on the wall [...] is another face, covered with white cloth" (Atwood, 1988, p. 267). In "Mirror Images in Margaret Atwood's Cat's Eye," Nicole Dejong maintains that the connection between Elaine and Cordelia is characterized by "Mirror images that divide them into self and other, subject and object, or two halves of a twin" (Dejong, 1998, p. 99).

Due to the haunting nature of Cordelia's memories of insult and criticism, Elaine hallucinates about Cordelia everywhere. She notes: "When I feel a touch on my arm, a chilly jump of the heart. Cordelia, I say turning. But it is not Cordelia. It is nobody I know" (Atwood, 1988, p.368). As time runs, Elaine declares that her bad memories with Cordelia returns to her consciousness in a form of a phantom, 
She has come back to me now in absolute clarity, acute in every detail, the outline of her hooded shape against the lights from the bridge, the red of her heart from within the cloak; I know this did not happen. There was only darkness and silence [...] I know that if I turn, right now, and look ahead of me along myself, in my old jacket, my blue knitted hat. But then I see that is Cordelia. She is standing halfway up the hill, gazing back over the shoulder [...] I know she is looking at me, the lopsided mouth smiling a little, the face closed and defiant (Atwood, 1988, p. 495).

At the beginning of the novel, Elaine is depicted as a character who is grappled with the tangled knots of her past memories. She is depicted as looking for her true "I." Elaine expresses that she: "will have her own version. I am not the center of the story, because she herself is that. But I could give her something you can never have, except from another person: what you look like from outside. A reflection: this is the part of herself I could give her back" (Atwood, 1988, p.485). This dense statement regarding the intersection between the double and the uncanny shows how Elaine's divided self-causes her to be obsessed with mirrors and reflections even in her adulthood. In order to release herself from the shackles of Cordelia's memories, Elaine strives to conciliate between her real self and her double, asserting that she "[is] headed for a future in which [she] stand [s] in the snow under the bridge, and stand and stand. While Cordelia vanishes and vanishes" (Atwood, 1988, p. 487).

\section{Dissociation in Atwood's Cat's Eye}

In The Body in Pain: the Making and Unmaking of the World, Elaine Scarry emphasizes the sufferings of traumatized individuals in various contexts. She specifies that trauma has devastating effects on the subject's mental state. In the same realm, in her study on trauma, Herman (1992) maintains that repeated traumatic events devastate the subject's coherent sense of the self. By using Scarry and Herman's views that traumatized subjects estrange themselves from their own selves due to the haunting nature of their trauma, the study refers to Elaine as detached and alienated from her body. Elaine reveals that due to the girls' bullying, she cannot overcome the feelings of fear and loneliness, deep insecurity and the lack of a coherent sense of self. Over the course of time, she becomes not only irritated by her powerlessness in front of them but she is also alerted by her abnormal behavioral reactions to their presence. From Herman's perspective, the girls' bad treatment, "shatter the construction of [Elaine's] self that is formed and sustained in relation to others and cast [her] into a state of existential crisis" (Herman, 1992, p. 37).

Bullying causes the narrator to suffer from depression, anxiety and low self-esteem. In order to cope with her friends' insults and criticism, Elaine, in her childhood, develops deviant or abnormal behaviors, like fainting, or pretending to faint in front of her tormenters. She considers this as defence mechanism: "I am beginning to feel I have discovered something worth knowing. There is a way out of places you want to leave but cannot. Fainting is like stepping sideways, out of your own body, out of time or into another time" (Atwood, 1988, p. 203). In another incident, Elaine induces loss of consciousness whenever she encounters unpleasant situations. As time runs, fainting becomes an automatic reaction to Elaine. Falling into the habit of rejecting food is another coping strategy that Elaine unconsciously deploys in front of the girls' taunts.

In "Self-Medication, Traumatic Re-enactments and Somatic Expression in Bulimic and SelfMutilating Behavior," Sharon Klayman Farber argues that "disordered eating and selfmutilating behavior, often in conjunction with dissociative states and substance abuse, seem to be behavior commonly used by survivors of trauma to cope with and adapt to the 
aftereffects of sexual or physical abuse, traumatic loss and separation" (Farber, 1997, p. 90). In the same realm, Barbara Friedman and Onno Van der Hart point out that anorexia nervosa is dissociative and hysterical in nature. They claim that "the attack of a fixed idea would be the inner commands an anorexic hears when trying to eat 'do not eat. You do not have the need to eat"' (Friedman \& Van der Hart 1989, p. 13). Here, one can say that Elaine's starvation falls in line with anorexia nervosa as a symptom of dissociation. Elaine deploys non-verbal language to convey her suffering. In "Somatic Expressions of Trauma in Experiential Play Therapy," Byron Norton et al., note: "by identifying the language of trauma in the body and by utilizing somatic attunement and reflection, [individuals] can access their implicit memories of traumatic events" (2011, p.150). Applying this to Elaine, one notices that Elaine has become unable to eat. She maintains that, each morning, she feels sick as the girls call for her. She declares that her "stomach feels dull and heavy, as if it is full of earth" (Atwood, 1988, p. 161). She adds that she starts to have a problem with her stomach. She unconsciously refuses and vomits any kind of food. In her narrative about her daily sufferings, she interjects the story of her play with Grace and how she starts vomiting:

[She] turn[s] aside and throw[s] up onto a snowboat. [She] did not mean to do it and did not know [she] was going to. [She] feel[s] sick to [her] stomach every morning. [She] used to that, but this is the real thing. [She] lie[s] in bed with the scrub pail beside [her], floating lightly on waves of fever. [She] throw[s] up several times; until nothing but a little green juice comes out. [She] begin[s] to be sick more often (Atwood, 1988, p. 162-63).

Her reaction itself is another ordeal. Suffering begets more suffering. Thus, Elaine's dissociative tendencies intensify when her body again tolerates food to the extent that whenever the girls call her, she automatically goes to eat in order to avoid their bullying.

Here, Elaine falls into the habit of over-eating; the way Joan does in Lady Oracle to resist her mother's authority. Farber (2002) notes that avoidance and over-eating are other coping strategies that traumatized subjects embrace in the face of stressful events. When Elaine returns from school, she both avoids and ignores the girls' taunts, thinking, "I can hear the hatred, but also the need. They need me for this, and I no longer need them. There is something hard in me, crystalline, a kernel of glass. I cross the street, eating my licorice" (Atwood, 1988, p. 229). In order to counter the girls' bullying, Elaine develops a "mean mouth": "I have such a mean mouth that I become known for it. I do not use it unless provoked, but then I open my mean mouth and short, devastating comments come out of it [...] the person I used my mean mouth on the most was Cordelia" (Atwood, 1988, p. 266-77). Elaine imagines that, in her adulthood, she will lose control over her mouth to the extent she will start walking with her mouth open. When she imagines her self being old, she finds the thought of "shedding hair and drooling while some younger spoons mushed food into [her] mouth" (Atwood, 1988, p. 487). The quote refers to Elaine's fear of heading for a future in which overeating destroys her life.

Self-harm is another defensive measure that the protagonist uses to cope with unpleasant situations. In Studies in Hysteria, Freud implies that dissociative behaviors are associated with hysterical persons who can neither regulate things nor control their stress. Freud provides us with the example of the hysteric woman who, due to her daily sufferings, keeps harming herself. He describes the case, saying "If nothing else she would do all sorts of mischief when alone in her room just to prove to herself that she was normal" (Freud, 2004, p. 243). As time runs, Elaine's coping strategies are no longer effective in regulating things around her; so she engages in other destructive and dissociative behaviors as cutting and purging. From Farber's 
perspective, cutting, starving, stuffing and purging give "a needed sense of control. Interpersonal and intra-psychic conflicts are displaced, concretized, and enacted within the psychic space that dissociates psyche from soma" (2002, p. 74). In Cat's Eye, Elaine, in her childhood, harms her body in order to assimilate with her daily stress, panic and fear. Atwood provides an abyssal and a graphic depiction of Elaine's act of peeling her skin:

In the endless time when Cordelia had such power over [her], [she] peeled the skin off [her] feet. [She] did it at night, when [she] was supposed to be sleeping. [Her] feet would be cool and slightly damp, smooth, like the skin of mushrooms. [She] would begin with the big toes. [She] would bend [her] foot up and bite a small opening in edge. Then, with [her] fingernails, which [she] never bit because why bite something that did not hurt, [she] would pull the skin off in narrow strips. [She] would do the same to the other big toe, then to the ball of each foot, the heel of each. [She] would go down as far as the blood. Nobody but [her] ever looked at [her] feet, so nobody knew [she] was doing it (Atwood, 1988, p. 134).

Elaine's behavior in harming herself is also projected through pulling her hair and gnawing her fingers, declaring that in order to forget about her fear of her bullies. She gnawed the cuticles off from around her fingernails; she "did these things constantly, without thinking about them. But the feet were more deliberate" (Atwood, 1988, p. 135).

Farber explains that "at the moment of self-harm and self-destructiveness, the suffering body feels most alive; at the moment of symbiotic merger with the internalized object, it also feels separate, cohesive and powerful" (2002, p. 169); so to Elaine, self-harm is not only a coping strategy but also a sense of empowerment in front of the girls' daily harassment to the extent that she thinks of "putting [her] finger in there, onto the red-hot grid" (Atwood, 1988, p. 141). It seems to give her a sense of satisfaction. As an illustration, Atwood describes the scene of Elaine's satisfaction in seeing blood in her forehead: "There is blood, I have cut my forehead. I am taken off to the nurse's office. The nurse wipes off the blood and sticks a wad of gauze onto me with a Band-Aid. The sight of my own blood on the wet white washcloth is deeply satisfying to me" (Atwood, 1988, p. 204). Through different incidents, Atwood indicates that Elaine becomes obsessed with harming her body. The narrator confirms that selfmutilation is a means through which she can cope with her current situation and feel "physical pain, to attach myself to daily life. My body is a separate thing. It ticks like a clock; time is inside it. It has betrayed me, and I am disgusted with it" (Atwood, 1988, p. 395).

The bullying involves all Elaine's sensory perceptions, forming one fixed idea that dominates her consciousness. When it arises, it leaves no room for other actions or thoughts. Over the course of time, Elaine's dissociation is not only projected through fainting, eating disorders and self-harm. Her non control over her body is another dissociative dimension. She asserts: "I feel as if my body is dissolving and I am being drawn up and up, like thinning mist, into a vast emptying space" (Atwood, 1988, p. 123). Elaine stresses that, due to Cordelia's criticism, her body unconsciously projects her stress, declaring "I believe each of these comments: my shoulders sag, my spine crumples, I exude the wrong kind of goodness; I see myself shambling crookedly, I make an effort to stand straighter, my body rigid with anxiety" (Atwood, 1988, p. 147). The notion of her dissolved body haunts her daily life and her dreams. Because of the tormentor, Cordelia, Elaine starts questioning her reality and her identity through mirrors. Elaine says, "I look into the mirror but I do not see anything out of the ordinary. It is just my face, with the dark blotches on the lips where I had bitten off the skin" (Atwood, 1988, p. 187). Due to Cordelia's bullying, Elaine expresses that she lives unworthy 
and meaningless life. She thinks to herself to become invisible: "I would come apart like that; I would be dead, like the dead people (Atwood, 1988, p. 185); as if to disappear has become her death wish, a solution.

As an author who accentuates the theme of familial relationship, Atwood engages in the subject of the child's need to the mother's attachment and intimacy by referring to Elaine's mother and her unawareness of how to bring up her daughter. Atwood underlines that Elaine's dissociative behaviors are a projection of her troubled childhood and how she lonely copes with those dramatic memories. Again, Atwood depicts how Elaine's mother systematically stigmatizes her daughter without putting into consideration her daughter's needs. The author further notes that the mother's unawareness of Elaine's suffering leads the daughter to wonder about her mother's attitudes. Elaine notes, "What would I have done if I had been my mother? She must have realized what was happening to me, or that something was. Even towards the beginning she must have noted my silences, my bitten fingers, the dark scabs on my lips where I had pulled off patches of the skin" (Atwood, 1988, p.178). The mother's disorientation about her daughter's sufferings cripples Elaine's psyche to the extent when she becomes a mother, she keeps verifying her daughters' feet, declaring that

As my daughters approached this age, the age of nine, I watched them anxiously. I scrutinized their fingers for bites, their feet, the ends of their hair. I asked them leading questions: Is everything all right, are your friends all right? And they looked at me as if they had no idea what I was talking about, why I was so anxious. I thought they have given themselves away somehow: nightmares, moping (Atwood, 1988, $p$. 139).

Through Elaine's sufferings due to her mother's maltreatment and unawareness of her daughter's needs, Atwood gives insight into the positive role of the healthy mother-daughter relationship since it contributes in constructing the child's coherent identity. By hinting to her mother's unawareness of her daily suffering at the hands of her bullies, Elaine indicates that her surroundings reject the notion of being a listener to her psychic wounds. Farber sheds light on how unspoken traumatic memories return to consciousness via somatic manifestations, specifying that childhood abuse can cause various psychic disorders including, "posttraumatic stress disorder, substance abuse, eating disorders, self-mutilation, dissociative disorders, and somatization" (Farber, 2002, p.112). In adulthood, Elaine, on the surface, seems to be content with her life but her crisis is shown through the haunting nature of the same feelings of detachment, insecurity, fear and panic.

\section{The somatic manifestation of Elaine's Trauma in Adulthood}

Elaine, as an aging woman, wishes that she can erase the memories of the girls' bullying from her consciousness since they keep haunting her. She asserts, "There are several diseases of the memory. Forgetfulness of nouns, for instance, or of numbers. Or these are more complex amnesias. With one, you can lose your entire past; you start afresh" (Atwood, 1988, p. 309). Elaine's detachment and inertia give her an urge to question the sources of her alienation. She declares, "I know that these things must be memories, but they do not have the quality of memories. They are not hazy around the edges, but sharp and clear. They arrive detached from any context; they are simply there, in isolation, as an object glimpsed on the street is there" (Atwood, 1988, p. 394). In her adulthood, Elaine unconsciously re-enacts those memories via dissociative behaviors. 
Different psychoanalytic studies have dealt with trauma and its haunting nature. In Writing History, Writing Trauma (2001), Lacapra argues that the persisting nature of traumatic memories immerses traumatized subjects in a time when they cannot distinguish between the past, the present and the future. He coins the terms of "acting out" and "working through," indicating that they are processes through which traumatized subjects repeat their traumatic experiences as fresh memories so that they can come to terms with their past. It is important to mention that Lacapra pinpoints that there is a connection between the two terms. At the same time, he explains that the process of acting out is different from working through in the way that in the acting out process, traumatized subjects repeat their original experiences as if they are other persons. Although Lacapra notes that the two processes are important for the subject to release from the shackles of different traumas, he acknowledges the limited scope of his approach, emphasizing that earlier trauma may occur again in various forms. The following extract summarizes Lacapra's theorization on trauma and his focus on the intersection between the two processes and how trauma is repeated. Lacapra says that the traumatized subject needs:

Going back to problems, working them over, and perhaps transforming the understanding of them. Even when they are worked through this does not mean that they may not recur and require renewed and perhaps changed ways of working through them again. In this sense, working through is itself a process that may never transcend acting out and that, even in the best of circumstances, is never achieved once and for all (Lacapra, 2001, pp. 148-49).

In Trauma and Recovery, Herman (2002, p. 69) explains that as a way to recover from trauma, traumatized subjects have to mourn their loss. She adds that the failure to "complete the normal process of grieving perpetuates the traumatic reaction" in different forms. In Cat's Eye, Elaine's inability to mourn her experiences with the girls intensifies the loss and fragmentation in her adulthood. As a facet of dissociation, self-mutilation serves two functions; it functions as a coping strategy for Elaine in her childhood. In her Adulthood, self-mutilation or self-harm is considered to be a reaction to the tormenting effects of her childhood trauma. As an adult, Elaine unconsciously harms herself as an enunciation of her childhood dramatic situations.

By remembering all the images of her past, Elaine acknowledges that the past never stays past; it rather reverberates throughout the entirely of her life via soma; particularly through dissociative actions and behavior. This argument can be illustrated by the incident of Elaine's interview with a journalist for her artistic retrospective. She starts picking on her nails since she imagines dialogues that are not taking place in the interview. She imagines someone telling her: "Your clothes are stupid. Your art is crap. Sit up straight and do not answer back" (Atwood, 1988, p. 106). Here, we learn that Elaine's strife to erase earlier traumatic memories proves to be a failure especially that those memories return to her consciousness in a dissociative form. This brings the idea that Elaine's coping strategies of her daily stress in her childhood have devastating ramifications. In the novel, Atwood portrays that Elaine, in adulthood, feels that she is "at the centre of nothingness [...] that is totally empty" (Atwood, 1988, p. 394). She adds that the narrator is "exploding slowly outward into the cold burning void of space" (Atwood, 1988, p. 394). One night, Elaine dreams that she enters a world of mirrors where she strives to resist her double Cordelia. She metaphorically gives her loss of identity to Cordelia, noticing: "I reach out my arms to her; bend down, hands open to show I have no weapon. It is all right. I say to her. You can go home now. The snow in my eyes withdraws like smoke" (Atwood, 1988, 
p. 495). This is obviously reminiscent of Anderson's story of "The Snow Queen" (1845) in which Kay enters a world of mirrors where he gets rid of the queen's chains with the help of Gerda. Although the aged Elaine lives in a troubled manner due to the haunting nature of her earlier traumatic memories, she ultimately comes to terms with herself by the end of the novel. In other words, she begins a process of producing a change in her life.

Different psychoanalytic studies highlight that healing from trauma takes different forms and mediums. Art has an important role in the process of healing from different psychic wounds. In order to ward off the fragmentation of the outer world and inner one, Elaine turns to painting as a shield from the traumatizing past and as a tool to heal from her earlier traumatic memories. To put it differently, she transforms her past memories of neglect, abandonment and bullying into art. She, for instance, reflects the bodily humiliations that she faced onto the pictures of Mrs. Smeath as a semi naked and vulnerable. Vickroy points out, "The paintings bear witness to the past [...] initially the images come from the involuntary and unconscious well of traumatic memory" (Vickroy, 1988, p. 134). Essentially, Elaine's reconstruction of her stormy life is projected in her painting entitled "Unified Field Theory" (Atwood, 1988, p.387), in which the "Virgin of Lost Things" (Atwood, 1988, p.481) appears by the ravine, holding the marble of the cat's eye. As Elaine concentrates on the painting, she sees her whole life as a unified field. To accentuate Elaine's reconstruction of her life, Atwood uses the metaphor of the bridge that foreshadows the protagonist's release of herself from all her suffering and traumatic memories that have both torn her apart and kept her living between the past and the present. Elaine refers to her reconstruction of herself, asserting: "I scrambled up. That is where I stood, with the snow falling on me, unable to summon the will to move. No one came walking on air down from the bridge; there was no lady in a dark cloak bending over me" (Atwood, 1988, pp. 494-495).

Elaine's experience of trauma is narrated by herself. This narration, therefore, becomes a personal testimony. One says that Cat's Eye is a literal as well as a metaphorical representation of trauma especially that the text functions as an outlet through which her trauma is embodied in its structural format. Elaine's personal testimony is characterized by no coherence; her narrative looks like random pieces that accentuate the physical dissociative manifestation of her troubled mind. Within the narrative, as Papatya Alkan Genca (2019, p. 140) asserts, there is a "deliberate focus on the interconnectedness of the mind and the body. The physical and the psychological mix and merge throughout the unconventional narrative." Atwood, throughout the novel, also incorporates food metaphors to illustrate that Elaine remains phobic to the word food even in her adulthood. Towards the closing pages of the novel, the narrator strives to forget about her earlier traumatic memories. She turns to painting as an outlet to express her detachment and to heal from her psychic wounds. Here, Elaine's unconscious is seen to be a source of creativity. By the end of the novel, it is shown that although Elaine's feelings of detachment and fragmentation are still haunting her, there is a speck of hope seeping through when she thinks of reconstructing her shattered self. She does a gesture of conciliation as she revisits the bridge where the girls used to meet. She succeeds in having a coherent identity. Additionally, she learns how to forget the past and to forgive Cordelia, "I am the older one now, I am the stronger. If she stays here any longer she will freeze to death; she will be left behind, in the wrong time. It is almost too late [...] I turn; finally, Cordelia is no longer there (Atwood, 1988, p.495-96). Here Elaine's words can, therefore, infer that she is on the mend, empowering herself.

\section{Conclusion}


Atwood's Cat's Eye is a novel of forgetfulness and reminiscence especially that the novel's main incidents show the effects of childhood trauma on Elaine. In the context of the different theorizations about trauma and its corporeal manifestations, the study ventures into emphasizing the connection between soma and trauma in Atwood's Cat's Eye. It shows that trauma is present throughout the text, highlighting the materiality of Elaine's traumatic memories. Her psychic wounds are present via her soma; her anorexic body, her bulimic behavior, separation from her body, her hallucination and her persistently chaotic memory, all attest to the thoroughly traumatized Elaine. The study also shows that Elaine's psychic wounds are embodied not only in the protagonist's body but also in the structure of the text. It significantly refers to Elaine's strife to reconstruct her divided and schizophrenic self via different mediums including painting.

\section{References}

Abraham, Nicolas, and Rand, Nicholas. (1987). Notes on the Phantom: A Complement to Freud's Metapsychology. Critical Inquiry. 13(2), 287-292. www.jstor.org/stable/1343493. Atwood, Margaret. (1988). Cat's Eye. London: Virago Press. (1996). Alias Grace. London: Virago Press.

(2002). Negotiating With the Dead: A Writer on Writing. Cambridge:

Cambridge University Press.

Banerjee, Chinmoy. (1990). Atwood's Time: Hiding Art in Cat's Eye. Modern Fiction Studies. 36 (4), 513-522.

Bouson, Brooks J. (1990). The Anxiety of Being Influenced: Reading and Responding to Characters in Margaret Atwood's The Edible Woman. Psychoanalysis, Gender, Genre. 24(2), 228-241.

Culbertson, Roberta. (1995). Embodied Memory, Transcendence, and Telling, Recounting Trauma, Re-establishing the Self. New Literary History. 26(1), 169-95. https://www.jstor.org/stable/20057274.

De Jong, Nicole. (1998). Mirror Images in Margaret Atwood's Cat's Eye. Nora: Nordic Journal of Feminist and Gender Studies. 6 (2), 97-107. https://doi.org/10.1080/08038749850167806.

Farber, Sharon Klayman.(1997). Self-Medication, Traumatic Re-enactments and Somatic Expression in Bulimic and Self-Mutilating Behavior. Critical Social Work Journal. 25, 87-106. https://doi.org/10.1023/A:1025785911606. . (2002). When the Body is the Target: Self-Harm, Pain, and Traumatic Attachments, New York: A Joson Aronson Book.

Freud, Sigmund.(2003). Beyond the Pleasure Principle and Other Writings. (Trans John Reddick), New York: Penguin Books. , and Breuer, Joseph. (2004). Studies in Hysteria. (Trans Nicola Luckhurst), New York: Penguin Books.

Galloway, Janice. (1989). The Trick is to Keep Breathing. London: Minerva.

Genca, Papatya Alkan. (2019). Corporeality of Trauma and Loss in Janice Galloway's The Trick is to Keep Breathing. Monograf, 11, 131-144.

Givner, Jessie. (1992). Names, Faces and Signatures in Margaret Atwood's Cat's Eye and The

Handmaid's Tale. George Woodcrock: An 80 th Birthday Collection. 133, 56-75.

Herman, Judith Lewis. (1992). Trauma and Recovery: the Aftermath of Violence-from Domestic Abuse to Political Terror. New York: Perseus Books Group.

Howell, Elizabeth F. (2005). The Dissociative Mind. New York: Routledge. 
Jones, Bethan. (2008). Traces of Shame: Margaret Atwood's Portrayal of Childhood, Bullying and its Consequences in Cat's Eye. Critical Survey. 20 (1), 29-42. DOI:10.3167/cs.2008.200104.

Kristeva, Julia. (1982). Powers of Horror: An Essay on Abjection. New York: Columbia University Press.

Lacapra, Dominick. (2001). Writing History, Writing Trauma. Baltimore: The Johns Hopkins University Press.

Lifton, Robert Jay. (1995). An Interview with Robert Jay Lifton. In: Cathy Caruth (Ed), Explorations in Memory. The Johns Hopkins University Press. 128-147.

Meese, Elizabeth. (1986). Crossing the Double-cross: the Practice of Feminist Criticism. Chapel Hill: University of North Carolina.

Nicolié, Milena. (2017). The Mirror Motif in Margaret Atwood's Cat's Eye. Belgrade Bells, 9(7),107-121. https://doi.org/10.18485/bells.2017.9.7

Norton, Byron, Ferriegel, Mark, and Norton, Carol. (2011). Somatic Expressions of Trauma in Experiential Play Therapy. International Journal of Play Therapy. 20 (3), 138-152. https://doi.org/10.1037/a0024349

Scarry, Elaine. (1985). The Body in Pain: The Making and Unmaking of the World. New York: Oxford University Press.

Schonfelder, Christa. (2013). (Re) Visions of the Buried Self: Childhood Trauma and Self Narration in Margaret Atwood's Cat's Eye. In: Haunted Narratives Life Writing in an Age of Trauma. University of Toronto Press. 257-273.

Van der Hart, Onno, and Friedman, Barbara. (1989). A Reader Guide to Pierre Janet on Dissociation: a Neglected Intellectual Heritage. Dissociation. 2 (1), 3-16.

Van der Kolk, Bessel A. (2014). The Body Keeps the Score. Brain, Mind, and Body in the Healing of Trauma. New York: Viking.

Vickroy, Laurie. (2005). Seeking Symbolic Immortality: Visualizing Trauma in Cat's Eye. An Interdisciplinary Critical Journal. 38 (2), 129-143. https://www.jstor.org/stable/44029436. 